\title{
Effect of fly ash geopolymer with $15 \%$ barium Sulphate as a design shielding box on radiation attenuation using Gafchramic $X R-Q A 2$ film dosimetry
}

\author{
Sabri M. Shalbi ${ }^{\mathrm{a}}$, M.S.Jaafar ${ }^{\mathrm{a}}$, Naser M. Ahmed ${ }^{\mathrm{a}}$, A.M. Al-jarrah ${ }^{\mathrm{b}}$, Abdullah. \\ Naji $^{\mathrm{a}}$, Ahmed AlsadigAhmed ${ }^{\mathrm{a}}$, M. A. Qaeed ${ }^{\mathrm{c}}$ \\ ${ }^{a}$ Medical Physics, School of Physics, UniversitiSains Malaysia, 11800 USM Penang, Malaysia \\ ${ }^{b}$ Sharjah Men's College, Higher Colleges of Technology, P.O. Box, Sharjah, United Arab Emirates \\ ${ }^{c}$ Physics Department, Faculty of Education, HodeidahUniversiti, Al-Hodeidah, Yemen.
}

\begin{abstract}
This work was devotedto examining the effects of fly ash geopolymer mixed with $15 \%$ Barium Sulphate on radiation attenuation using Gafchramic XR-QA2 film. The fly ash geopolymer with $15 \%$ Barium Sulphate made high attenuation at energy of $120 \mathrm{KVp}$. In this study, the maximum radiation attenuation value of $99.43 \%$ was obtained by the design shielding box. The X-ray machine was used as a source for X-rays. While the Gafchramic XR-QA2 film dose was measured by the optical density equation, the ion chamber is used for dose measurement.
\end{abstract}

Key words: Fly ash geopolymer; $\mathrm{BaSO}_{4}$; Attenuation coefficient; Gafchramic XR-QA2 film; Ion chamber

\section{INTRODUCTION}

Fly ash is a low-cost material that is available for researchers and can be used to construct the shielding instead of some high cost materials such as Lead and concrete. On the other hand, using cement Portland in Xray room wall can result in carbon dioxide emissions, accounting for $5 \%$ of global carbon dioxide production or approximately 1.5 tons per year [1]. In addition to this problem related to the use of cement Portland in X-ray room wall, several drawbacks have been reported to be connected to the use of concrete. Such drawbacks can considerable variability in its composition and water content. One possible alternative to be used in X-ray room walls is the use of alkali activated binders using fly ash. An added benefit is to convert a waste product into a useful product radiation protection shields. Since a larger quantity of shielding material is required for purposes of radiation shielding, examining the propagation of radiation flux in shielding materials is an essential requirement for better shield design [2].Geopolymers have also been shown to have a good bond strength to OPC concrete. Taking this into account, they can be considered to be a good repair material with superior abrasion resistance [3]. Furthermore, Geopolymers have many excellent properties such as resistance, low shrinkage, and high compressive strength [4]. Geopolymers were fabricated from fly ash which is a solid residue arising from coal burning thermal power stations. Thus, it is very beneficial in terms of environmental impacts [4]. Fly ash geopolymers have been prepared as geopolymer mortars [5].Fly ash based geopolymer mortars are less susceptible to alkali-aggregate reaction because the lower calcium content in these systems results in a reaction product that is not expensive [6,7]Geopolymer is alkali-activated binder produced by a polymerization reaction of alkaline liquids with the silicon and the aluminum oxides in source materials of geological origin like product materials such as fly ash [8]. It is also well-known that geopolymers possess excellent mechanical properties and fire resistance [9]. Geopolymers, in general, present a low thermal conductivity at high temperatures [10-13] and they do no emitted toxic fume when it is heated [14]. The fly ash geopolymer has good properties that allow it to be used as the shield, adding other materials such as barium sulphate to fly ash geopolymer to increase density and to improve the attenuation characteristics. Barium Sulphate $\mathrm{BaSO}_{4}$ is the material used in this work to test its ability in radiation absorption in order to make radiation protection by mixing Barium Sulphate with fly ash geopolymer mortar. It is primarily used as a whitening agent and as an insoluble support in industrial applications [15]. The novelty in this work is related to the use of fly ash geopolymer as shielding material with $15 \%$ Barium Sulphate as a design shielding box.The measurement of the dose by calculating the mass attenuation coefficient using Gafchromic XR-QA2 film and ion chamber.

II.

MATERIALS

The materials were utilized in this study including X-ray machine as a source of radiation exposure, dosimeter consist of calibrated ion chamber and electrometer, fly ash geopolymer with $15 \%$ Barium Sulphate shielding box,Gafchromic XR-QA2film as it shown in Figure 1. 


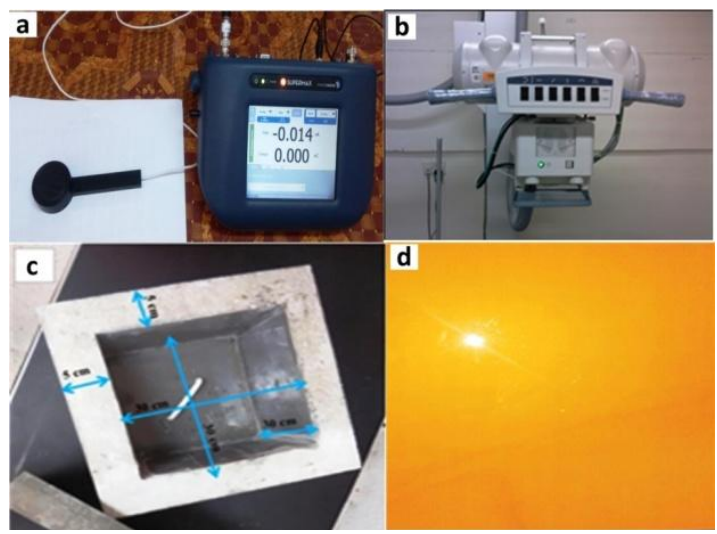

Figure 1: The Materials utilized in this study; (a) Ion chamber and electrometer, (b) X-ray tube, (c) Fly ash with $15 \%$ of barium Sulphate shielding box (d) GafchromicXR-QA2 film dosimetry

\section{METHOD}

In the fabrication of fly ash geopolymer shielding box is consist of 2 boxes internal and external. The internal box with dimensions of $(20 \times 20 \times 20) \mathrm{cm}^{3}$ and the external box with $(30 \times 30 \times 30) \mathrm{cm}^{3}$ shown in Figure 2(a). The internal box was placed inside the external box. The distance between them is $5 \mathrm{~cm}$ in each side.
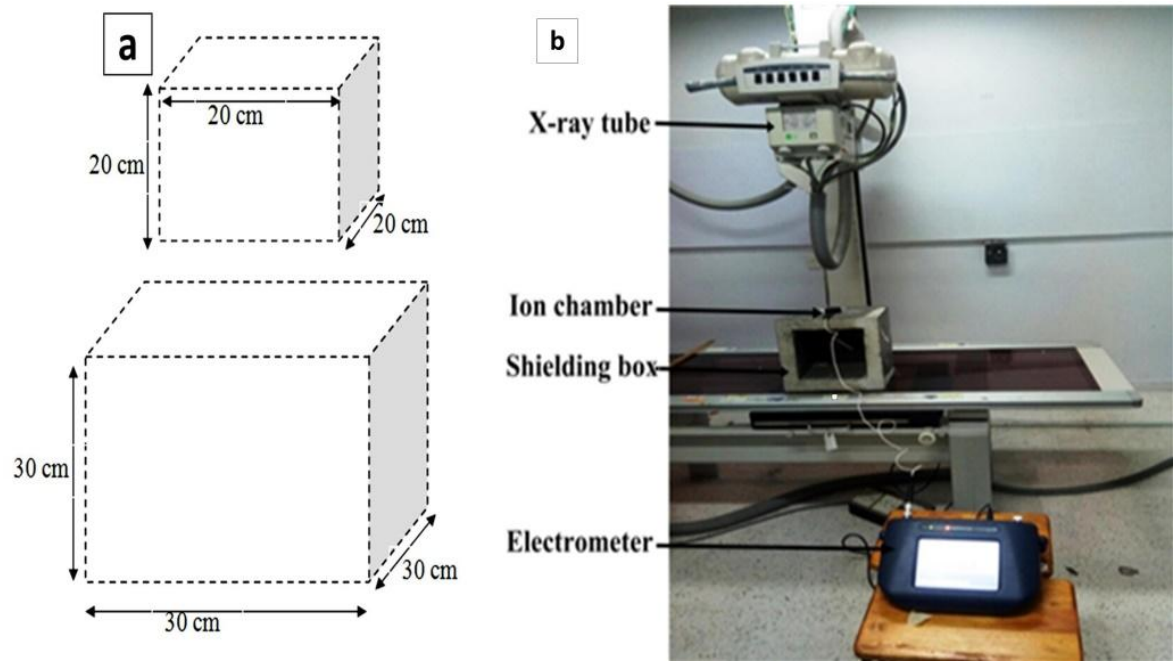

Figure 2: Experiment set up

This distance was filled with the fly ash geopolymer with $15 \%$ Barium Sulphate material. The boxes filled with fly ash geopolymer $+15 \%$ Barium Sulphate material were kept for three days to dry. The boxes were detached from the fly ash material and kept in the oven at $60^{\circ} \mathrm{C}$ for 24 hours. After this, they were ready for investigation, as shown in Figure 2 (b). This experiment was performed to determine the safety level of radiation, then the fly ash shielding box is used as a radiation protection.

\section{RESULTS AND DISCUSSION}

The effect of attenuating radiation on film exposure and film optical density was investigated. The Gafchromic XR_QA2 film was exposed to radiation with and without a fly ash geopolymer shield. The results show a direct relation between film optical density and film exposure to radiation. The fly ash geopolymer with $15 \% \mathrm{BaSO}_{4}$ significantly reduced radiation exposure when used as a shield between X-ray source and film, as shown in Figure 3. Nonetheless, the X-ray attenuation ability of fly ash shield decreases with increasing X-ray tube voltage due to the fact that increasing the photons energy of X-ray simultaneously increases its ability to penetrate protection shields. 


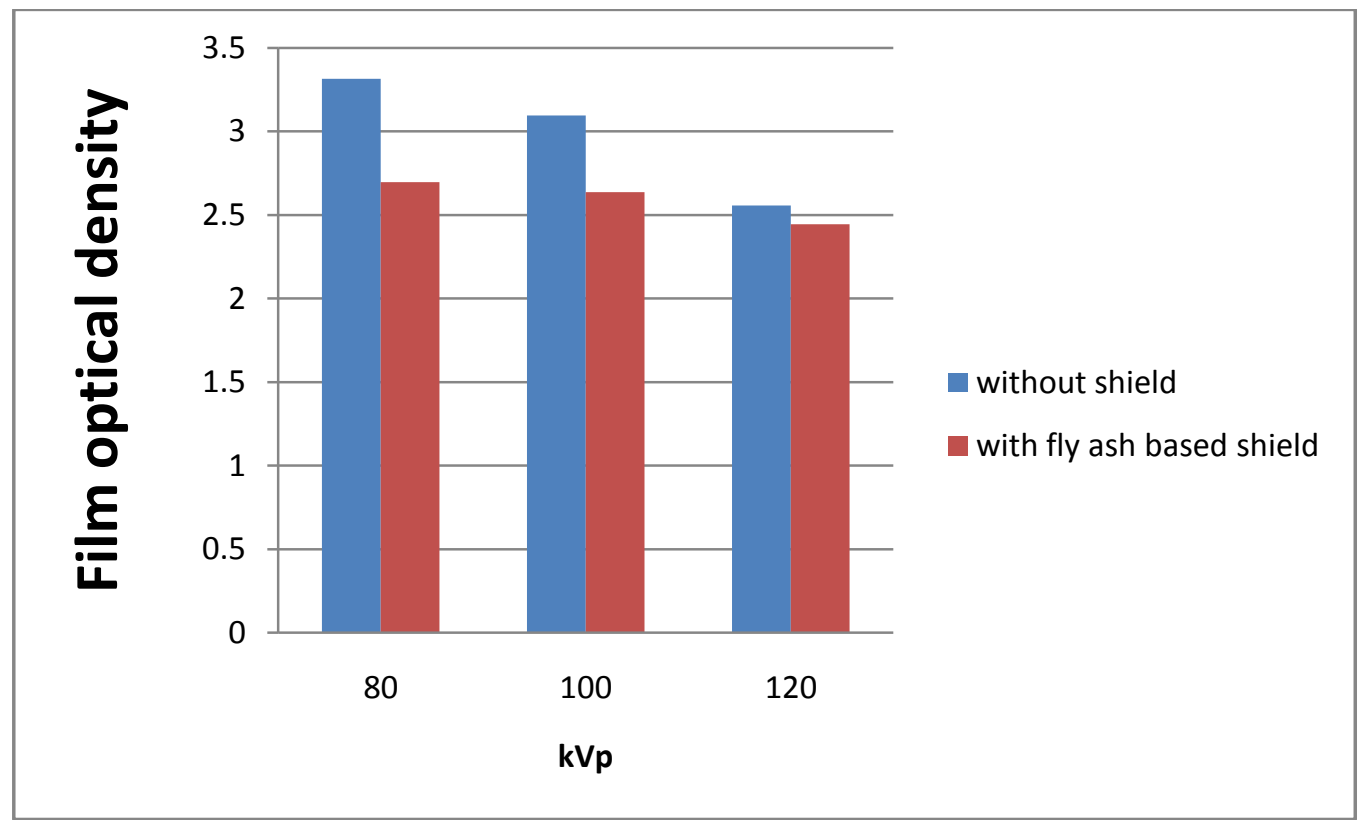

Figure 3: Film exposure and optical density

The exposed dose on film was measured using the ion chamber dosimeter at different X-ray energies, with and without a shield. This evaluation was conducted in order to assess the effect of Barium Sulphate on the X-ray attenuating ability of fly ash shield. The exposed dose on film, with and without fly ash geopolymer with $+15 \% \mathrm{BaSO}_{4}$ shield was evaluated as a function of X-ray tube voltage (Figure 4). The results show that optimum attenuation by the fly ash shield was achieved at low X-ray energy because radiation penetration through fly ash shield increases with increasing X-ray photon energy.

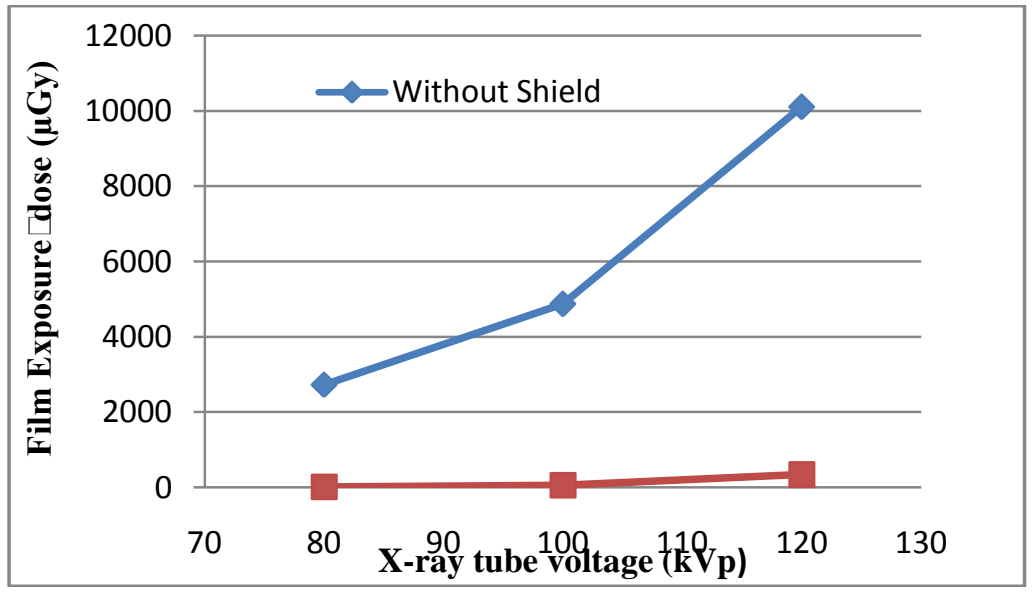

Figure 4: Film exposure at different x-ray tube voltage

To determine the ability of fly ash shields to reduce the penetration of transmitting radiation, the percentages of attenuating radiation at different X-ray energies were calculated, as shown in Figure 5. Maximum radiation attenuation value of $99.43 \%$ was obtained at low X-ray energy of $80 \mathrm{kVp}$, while a lower attenuating percentage of approximately $96.58 \%$ was recorded at relatively higher X-ray energy $(120 \mathrm{kVp})$. 


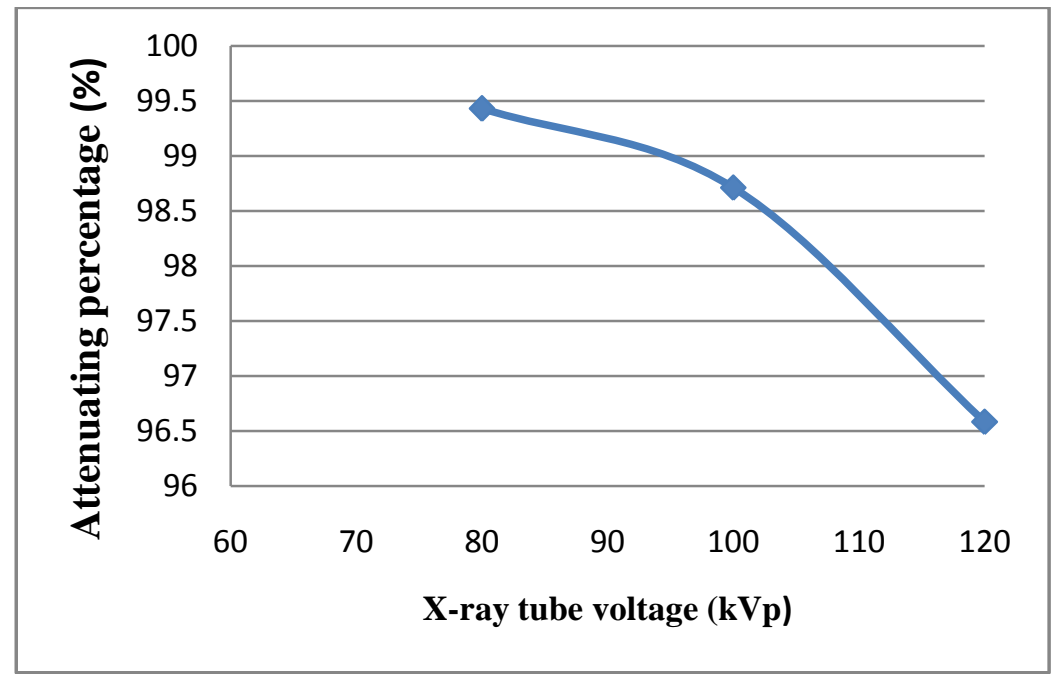

Figure 5: X-ray attenuation by fly ash based shield at different $\mathrm{kVp}$

The attenuation ability of fly ash was found to decrease with increasing incident X-ray photon energy. Nonetheless, at high X-ray energy $(120 \mathrm{kVp})$; more than $96.5 \%$ of incident radiation was attenuated. Thus , the relation between optical density and film exposure was investigated (Figure 6) presents a plot of film optical density against film exposure dose. The graph shows there is a direct relation between film exposure and optical density, i.e. increasing incident photons on film causes more darkness and increases optical density.

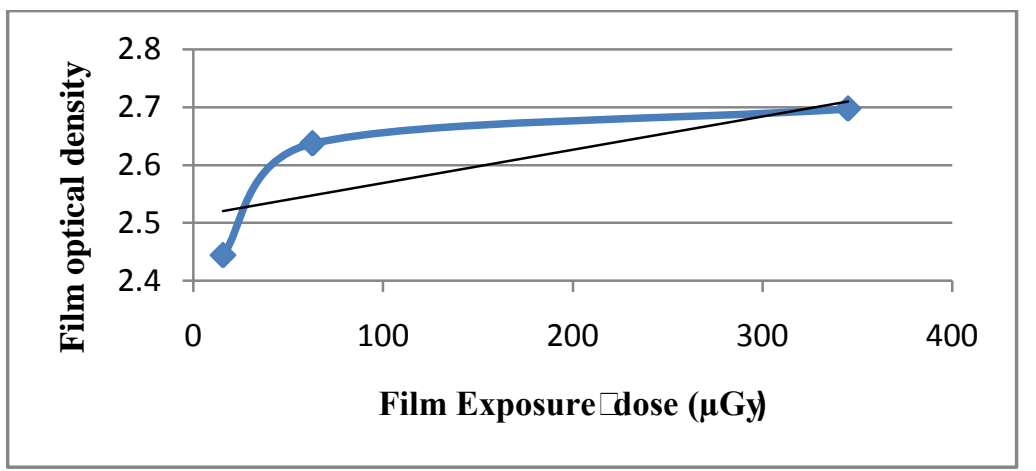

Figure 6: Relation between film exposure and optical density of film

The results illustrate that increasing film exposure gradually increases optical density until it reaches saturation value while, increasing incident exposure causes a relatively lower rise in optical density.

\section{CONCLUSION:}

The design of fabrication used in this study is the shielding box. This design is the major contribution of this study. It has been designed as a box for the prevention of radiation based on the best results from the fly ash geopolymer thickness. The design shielding box performance was evaluated by X-ray experiment and by using various energies such as high X-ray energy $(120 \mathrm{kVp})$. In this study, the attenuation percentage recorded high percentage more than $96.5 \%$ of incident radiation. Additionally, we found that the fly ash geopolymer can have the possibilityofreplacing the cement shielding. In addition, to the ratio of $15 \%$ of $\mathrm{BaSO}_{4}$ added to the fly ash geopolymer achieved improvement in the radiation protection by fly ash geopolymer.

\section{ACKNOWLEDGEMENT:}

I wish to thank UniversitiSains Malaysia for supporting this work, special thank goes to Prof. Dr. Mohamad SuhaimiJaafar for his feedback and comments, Also Higher Institute medical professions khoms and ElmergibUniversity, of Libya for awarding the scholarship to assist my pursuit of a $\mathrm{PhD}$.

\section{REFERENCES}


[1] Kotwal, A.R., et al., Characterization and early age physical properties of ambient cured geopolymer mortar based on class $C$ fly ash. International Journal of Concrete Structures and Materials, 2015. 9(1): p. 35-43.

[2] Singh, N., et al., Comparative study of lead borate and bismuth lead borate glass systems as gammaradiation shielding materials. Nuclear Instruments and Methods in Physics Research Section B: Beam Interactions with Materials and Atoms, 2004. 225(3): p. 305-309.

[3] $\mathrm{Hu}, \mathrm{S}$., et al., Bonding and abrasion resistance of geopolymeric repair material made with steel slag. Cement and concrete composites, 2008. 30(3): p. 239-244.

[4] Hardjito, D., Studies of fly ash-based geopolymer concrete. 2005: Curtin University of Technology.

[5] Lee, W. and J. Van Deventer, The interface between natural siliceous aggregates and geopolymers. Cement and Concrete Research, 2004. 34(2): p. 195-206.

[6] García-Lodeiro, I., A. Palomo, and A. Fernández-Jiménez, Alkali-aggregate reaction in activated fly ash systems. Cement and Concrete Research, 2007. 37(2): p. 175-183.

[7] Fernández-Jiménez, A., I. Garcia-Lodeiro, and A. Palomo, Durability of alkali-activated fly ash cementitious materials. Journal of Materials Science, 2007. 42(9): p. 3055-3065.

[8] Davidovits, J., Chemistry of Geopolymeric Systems, Terminology In: Proceedings of 99 International Conference. eds. Joseph Davidovits, R. Davidovits \& C. James, France, 1999.

[9] Palomo, A., et al. Physical, chemical and mechanical characterization of geopolymers. in Proceedings of the 9th International Congress on the Chemistry of Cement, New Delhi, India. 1992.

[10] Lyon, R.E., et al., Fire-resistant aluminosilicate composites. Fire and materials, 1997. 21(2): p. 67-73.

[11] Duxson, P., G.C. Lukey, and J.S. van Deventer, Thermal evolution of metakaolin geopolymers: Part 1Physical evolution. Journal of Non-Crystalline Solids, 2006. 352(52): p. 5541-5555.

[12] Zuda, L., et al., Thermal properties of alkali-activated slag subjected to high temperatures. Journal of Building Physics, 2007. 30(4): p. 337-350.

[13] Rovnaník, P., P. Bayer, and P. Rovnaníková, Characterization of alkali activated slag paste after exposure to high temperatures. Construction and Building Materials, 2013. 47: p. 1479-1487.

[14] Duxson, P., G.C. Lukey, and J.S. van Deventer, Thermal conductivity of metakaolin geopolymers used as a first approximation for determining gel interconnectivity. Industrial \& engineering chemistry research, 2006. 45(23): p. 7781-7788.

[15] Bushberg, J.T., et al., The Essential Physics of Medical Imaging, Lippincott Williams \& Wilkins. Philadelphia, USA, 2002. 